\title{
Environmental health reform in a synthetic world
}

\author{
Shetal Shah ${ }^{1}$, Shale Wong ${ }^{2}$, Cynthia Bearer ${ }^{3}$ and Heather Brumberg ${ }^{1}$
}

A voidance of pollutants, defined as manmade chemicals, is virtually impossible in the modern era. Worldwide, there are up to 100,000 chemicals used commercially, and production of each and development of new ones are annually increasing (1). Use of agricultural pesticides reached 2.4 billion kilograms globally (2). Use of these pollutants imparts significant healthcare associated worldwide. Cost of pesticide use in Africa is estimated at $\$ 66$ billion, and predicted cost to treat the impact of a small number of these chemicals in Europe is $\$ 179$ billion annually $(1,3)$.

In the United States, 12.25 trillion kilograms were produced or imported in the first part of the decade, and $\sim 80,000$ chemicals were used, incurring $\$ 76.6$ billion in pediatric environmental healthcare costs $(4,5)$. In this issue, three articles utilizing different populations underscore the potential vulnerabilities of children to environmental pollutants. In the first article, using data from three mother-baby cohorts that assessed markers of endocrine-disrupting chemicals in cord blood and/or breastmilk, de Cock et al. (6) found a nonlinear association between levels of polychlorinated biphenyl153 and dichlorodiphenyldichloroethylene with lower neonatal thyroid-stimulating hormone values on heel prick screening. In the second article, Harley et al. (7) found positive associations between prenatal levels of urinary phthalates, which are used in personal care products and plastics, and subsequent obesity in offspring at 12 years of age. Finally, in the third article, Chang et al. (8) found a link between prenatal maternal exposure to volatile organic compounds that can be released from substances such as solvents and paints, and reduced birthweight (9).

Children are uniquely susceptible to chemical exposures $(1,4,10,11)$. These three studies highlight several key aspects of environmental pollutants on child health:

(1) They illustrate that toxic exposure may occur at detectable levels through multiple portals of entry, including air, skin, and ingestion.

(2) The developing fetus may be especially sensitive to potential health effects from transplacental passage or preconceptual exposure $(1,4,12)$.

(3) The effects of exposure during development may not be realized until adolescence and/or adulthood.
Governments, on behalf of their peoples, bear significant responsibility to ensure that populations are not adversely affected by chemical compounds, if one accepts that protecting public health is of vital national interest $(13,14)$. As such, governments are entitled to instituting evidencedbased measures that protect health $(13,15,16)$. In the United States, protection against the harmful effects of chemicals is the responsibility of the Environmental Protection Agency (EPA) under the 1976 Toxic Substances Control Act (TSCA), which was updated in $2016(17,18)$. Regulation by EPA in other areas has had tangible effects. For example, the implementation of the National Ambient Air Quality Standards has improved air quality and reduced the percentage of children exposed to threatening levels of particulate matter, sulfur dioxide, and ozone (19). These standards have translated into better health outcomes, as demonstrated by Laden et al. (20).

The 2016 update in part served to address several weaknesses of the original law. The TSCA did, for instance, not mandate a specific schedule of tests to be conducted for safety prior to allowing the use of newly introduced chemicals (21). The original law also required the EPA to consider the financial burden on the companies to implement any regulations, which meant that under the old law the EPA could not even ban asbestos $(4,21)$. Further, the law did not explicitly require testing of vulnerable populations, and grandfathered over 60,000 chemicals $(4,21,22)$. Under the TSCA, companies could withhold information about toxicity by labeling such data "Confidential Business Information," as a modified trade-secret $(4,22)$. In practice, this meant that under the old law, the EPA's hands were essentially tied, limiting the protection of the public from unsafe chemicals.

Due to the limitations of the 1976 law, particularly the influence of industry and the high burden placed on the agency to illustrate potential risk to force additional safety testing, TSCA was reformed in 2016 under the Frank R. Lautenberg Chemical Safety for the 21st Century Act (23).

Under the TSCA update, new chemicals must have an EPA safety determination prior to entering the market, and the EPA retains power to institute phase outs and bans or limitations if substances are deemed unsafe or in need of more study (23). The update also enacts restrictions for information that may be termed "Confidential Business

\footnotetext{
'Division of Neonatology, Department of Pediatrics, New York Medical College, Maria Fareri Children's Hospital, Valhalla, New York; ${ }^{2}$ University of Colorado Denver School of Medicine, Aurora, Colorado; ${ }^{3}$ Division of Neonatology, Department of Pediatrics, University of Maryland, School of Medicine, Baltimore, Maryland. Correspondence: Shetal Shah (shahs2@wcmc.com)

Received 6 June 2017; accepted 7 July 2017; advance online publication 2 August 2017. doi:10.1038/pr.2017.168
} 


\section{Commentary | shah et al.}

Information." Finally, to finance these regulations, the agency may collect up to $\$ 25$ million as user fees from chemical producers. Many of these tenets have been introduced with an aggressive timeline, as the agency was required to begin prioritizing chemicals within 6 months of passage, with evaluation of 10 high-priority chemicals over the next 3 years $(21,24)$.

However, the 2016 law update has several limitations. Many of the regulations are vague and may require judicial interpretation $(17,18,24)$. The law does not mandate a series of safety tests, in contrast to requirements for a new pharmaceutical $(17,24)$. The law also does not adequately address the work-around of "regrettable substitution," where a banned chemical could be replaced by manufacturers with a similar agent without separate, independent safety testing (12,25). Further, increased restraint also is placed on the ability of States to supersede EPA determinations of safety and implement rules regarding chemicals under active EPA evaluation $(21,23)$. Given the constraints of the TSCA, many States have acted in the absence of federal legislation (26). States have passed or proposed limitations on commonly produced chemicals, including phthalates and Bisphenol A (21).

Threats from the current Administration to reduce EPA funding further compound concerns over whether the EPA is sufficiently financed to satisfy its increased responsibilities under the TSCA reform $(24,27)$. The potential revenue from user fees does not begin to reflect the billions in costs associated with a single group of chemicals such as endocrine disrupters $(3,28)$. Increased responsibilities under the reform may not translate into protection for those lower on the socioeconomic ladder, who disproportionately bear the burden of toxicant exposure $(1,26)$. In this issue, Harley's study of phthalates in a largely low-income, Mexican immigrant population emphasizes that those in poverty endure a disproportionate burden of health consequences of toxicant exposures and thus require special attention (26). This inequity is especially true internationally. Less-developed countries bear a greater burden of health effects of pollution compared with wealthier countries. Trade agreements facilitate this discrepancy as production of chemicals is outsourced to poorer nations (1).

As the effects of the TSCA reforms begin to be understood, pediatricians must increase their attention to environmental influences on child health. The science underlying these exposures, as well as the processes of law reform, is complex. Unfortunately, despite increasing awareness of the influence of chemicals on health, few physicians feel competent to discuss these issues with patients $(29,30)$. Pediatric Environmental Health Specialty Units (PEHSUs), a network of academically based programs, provide environmental health experts for consultation, serving as a referral source for practicing clinicians (31). PEHSUs also provide community and educational resources for clinical support related to environmental health. This additional knowledge can (or should) help pediatricians better advocate for environmental health policies that protect children and families.

In addition to clinical resources, more research such as the studies highlighted in this issue is necessary, specifically longitudinal research on chemicals/mixtures of chemicals and health outcomes from birth over the life course and across generations $(1,4,12,28)$. Yet, from 2003 to 2015, the National Institutes of Health $(\mathrm{NIH})$ experienced a $22 \%$ reduction in funding capacity relative to inflation (32) thus affecting funding for pediatric research. Although Fiscal Year 2017 Appropriations saw a $\$ 2$ billion increase in the overall $\mathrm{NIH}$ funding, this step just inches toward restoring cumulative funding losses due to two decades of reduced appropriations and the 2012-13 Federal Sequester. Over the same time period, the National Institute of Environmental Health Sciences also experienced a $13 \%$ reduction in funding relative to inflation, and appropriations have been stagnant for the past 3 years $(33,34)$. Proposed budgets for 2018 could be devastating to the environmental health research with potential cuts to NIH of $27 \%$ (more than $\$ 7$ billion), including a $\$ 33.6$ million reduction to the Environmental Influences on Child Health Outcomes.

The 2016 TSCA reforms were a needed advancement toward comprehensive regulation of our modern, increasingly polluted world. However, knowledge regarding TSCA without understanding the subtleties of reform may lead to a misinformed complacency that legislation has resolved many outstanding issues. With strong advocacy from pediatricians, increased awareness of the influence of chemicals on pediatric and reproductive health will allow child health providers to better inform legislators and policy makers. Ultimately, pediatricians should seek a strong, fiscally responsible infrastructure for pre-market evaluation of all chemicals coupled with a system that provides continued surveillance of potential health consequences over generations. As these studies illustrate, our ubiquitous chemical exposures may translate to our children's disease burden.

\section{ACKNOWLEDGMENTS}

We acknowledge the manuscript review by Ami Gadhia from the American Academy of Pediatrics for her review of the manuscript.

Disclosure: The authors declare no conflict of interest.

\section{REFERENCES}

1. Di Renzo GC, Conry JA, Blake J, et al. International Federation of Gynecology and Obstetrics opinion on reproductive health impacts of exposure to toxic environmental chemicals. Int J Gynecol Obstet 2015;131:219-25.

2. Grullón G. Infographic: pesticide planet. Science 2013;341:730-1.

3. Trasande L, Zoeller RT, Hass U, et al. Estimating burden and disease costs of exposure to endocrine-disrupting chemicals in the European Union. J Clin Endocrinol Metab 2015;100:1245-55.

4. Council on Environmental Health. Chemical-management policy: prioritizing children's health. Pediatrics 2011;127:983.

5. Trasande L, Liu Y. Reducing the staggering costs of environmental disease in children, estimated at \$76.6 billion in 2008. Health Aff 2011;30:863-70.

6. de Cock M, de Boer M, Govarts E, et al. Thyroid stimulating hormone levels in newborns and early life exposure to endocrine disrupting 


\section{Toxic Substances Control Act Commentary}

chemicals-analysis of three European mother-child cohorts. Pediatric Research 2017 (this issue).

7. Harley MG, Berger KM, Rauch S, et al. Association of prenatal urinary pthalate metabolite concentrations and childhood BMI and obesity. Pediatr Res 2017 (this issue).

8. Chang M, Park H, Ha M, et al. The effect of prenatal TVOC exposure on birth and infantile weight: the Mother's and Children's Environmental Health (MOCEH) study. Pediatr Res 2017 (this issue).

9. Tox Town: Volatile Organic Compounds (VOCs). (https://toxtown.nlm. nih.gov/text_version/chemicals.php?id=31.) Accessed 23 May 2017.

10. Makri A, Goveia M, Balbus J, Parkin R. Children's susceptibility to chemicals: a review by developmental stage. J Toxicol Environ Health B Crit Rev 2004;7:417-35.

11. World Health Organization Children's Health and the environment: a global perspective, 2005 (http://apps.who.int/iris/bitstream/10665/43162/ 1/9241562927_eng.pdf) Accessed 7 May 2017.

12. The TENDR Consensus Statement. Project TENDR: Targeting environmental neuro-developmental risks. Environ Health Perspect 2016;124:A118-22.

13. Mello MM, Studdert DM, Brennan TA. Obesity-the new frontier of public health law. N Engl J Med 2006;354:2601-10.

14. Mello MM, Studdert DA, Parment W. Shifting Vaccination Politics-The End of the Personal-Belief Exemption in California. N Engl J Med 2015;373:785-7.

15. Food and Drug Administration Overview of the Family Smoking Prevention and Tobacco Control Act, 2015 (http://www.fda.gov/downloads/Tobacco Products/Labeling/RulesRegulationsGuidance/UCM336940.pdf) Accessed 22 August 2016.

16. Silbergold EK, Mandrioli D, Cranor CF. Regulating chemicals: law, science, and the unbearable burdens of regulation. Annu Rev Public Health 2015;36:175-91.

17. Schmidt CW. TSCA 2.0: a new era in chemical risk management. Environ Health Perspect 2016;124:A182-6.

18. Hamblin J. Toxic Substances Will Now Be Somewhat Regulated. The Atlantic, 2016. (https://www.theatlantic.com/health/archive/2016/05/toxicsubstances-control-act/484280/) Accessed 7 May 2017.

19. Environmental Protection Agency America's Children and Environment: Environments and Contaminants-Criteria Air Pollutants (https://www. epa.gov/ace/ace-environments-and-contaminants-criteria-air-pollutants) Accessed 22 May 2017.

20. Laden F, Schwartz J, Speizer FE, Dockery DW. Reduction in fine particulate air pollution and mortality: extended follow-up of the Harvard Six Cities Study. Am J Respir Crit Care Med 2006;173:667-72.

21. Transande L. Updating the toxic substances control act to protect human health. JAMA 2016;315:1565-6.
22. Lowry J. Environmental Stakeholder Meeting on TSCA New Chemicals Program, 14 December 2016.

23. Environmental Protection Agency Highlights and Key Provisions in the Frank R Lautenberg Chemical Safety for the 21st Century Act (https:// www.epa.gov/assessing-and-managing-chemicals-under-tsca/highlights-keyprovisions-frank-r-lautenberg-chemical) Accessed 21 May 2017.

24. Vandenberg LN. Reform of the Toxic Substances Control Act (TSCA): an endocrine society policy perspective. Endocrinology 2016;157: 4514-5.

25. Shelton JF, Geraghty EM, Tancredi DJ, et al. Neurodevelopmental disorders and prenatal residential proximity to agricultural pesticides: the CHARGE Study. Environ Health Perspect 2014;122:1103-9.

26. Goldman L, Tran N. Toxics and Poverty: the Impact of Toxic Substances on the Poor in Developing Countries (http://www-wds.worldbank.org/ external/default/WDSContentServer/WDSP/IB/2008/07/21/000333037_ 20080721022854/Rendered/PDF/445580WP0BOX0327404B01PUBLIC1.pdf) Accessed 20 May 2017.

27. Dennis B, Eilperin J. EPA Remains Top Target with Trump Administration Proposing 31 Percent Budget Cut. Washington Post, 23 May 2017. (https://www.washingtonpost.com/news/energy-environment/ wp/2017/05/22/epa-remains-top-target-with-trump-administration-proposing31-percent-budget-cut/?utm_term $=.03630 f 6053 d 9)$ Accessed 25 May 2017.

28. Zoeller RT, Brown TR, Doan LL, et al. Endocrine-disrupting chemicals and public health protection: a statement of principles from The Endocrine Society. Endocrinology 2012;153:4097-110.

29. Stotland NE, Sutton P, Trowbridge J, et al. Counseling patients on preventing prenatal environmental exposures-a mixed methods study of obstetricians. PLoS ONE 2014;9:e98771.

30. Zachek CM, Miller MD, Hsu C, et al. Children's cancer and environmental exposures: professional attitudes and practices. J Pediatr Hematol Oncol 2015;37:491-7.

31. Pediatric Environmental Health Specialty Units Education and Resources (http://www.pehsu.net/education.html) Accessed 21 May 2017.

32. Federation of American Societies for Experimental Biology NIH Research Funding Trends (http://www.faseb.org/Science-Policy-and-Advocacy/ Federal-Funding-Data/NIH-Research-Funding-Trends.aspx) Accessed 10 May 2017.

33. Department of Health and Human Services 2018. Justification of Estimates for Appropriations Committees 2017 (https://officeofbudget. od.nih.gov/pdfs/FY18/NIH\%20Overview\%20Volume\%20Final.pdf) Accessed 23 May 2017.

34. National Institutes of Health Office of Budget National Institutes of Health Historical Budget Request (https://officeofbudget.od.nih.gov/ history_budget_req.html) Accessed 20 May 2017. 